\title{
Um jogo de tabuleiro humano para auxiliar a aprendizagem de Geologia e Paleontologia na educação básica
}

\author{
A human board game to help in teaching Geology and Paleontology in high school \\ Priscilla Dála S. Alves \\ Bióloga licenciada pela Faculdade Técnico-Educacional Souza Marruues. Rio de Janelro, RJ. E-mall: priscllLadalia@yahoo.com.Br
}

\begin{abstract}
The present work proposes to verify, in the teaching of biological sciences in basic education (high school), the association between the contents of geopaleontology and evolution, and to study whether the students are able to relate the theoretical concepts learned in class with the events/phenomena that actually occurred millions of years ago, including the birth of planet Earth. By means of a ludic activity - a human board game with questions and answers -, this work sought to analyze and answer the frequent doubts that arise during the game. It was also observed that the game resulted in new learning, and how well students assimilated it.
\end{abstract}

\section{Introdução}

O presente trabalho foi criado a partir de observações das aulas de biologia do estágio curricular obrigatório da instituição de ensino, Faculdade Técnico-Educacional Souza Marques, e que foi realizado no colégio Instituto Padre Leonardo Carrescia. As unidades localizam-se na cidade do Rio de Janeiro, RJ. Verificou-se que o ensino de Geologia e Paleontologia é oferecido de acordo com o nível das séries da educação básica seguindo os Parâmetros Curriculares Nacional: o $6^{\circ}$ ano do ensino Fundamental II tem como objetivo o ensino de Geologia, fundamentando-se nas principais características do solo; $7^{\circ}$ ano do ensino Fundamental II já visa associar as teorias evolutivas de Lamarck, Darwin e outros à evolução do planeta Terra; o $1^{\circ}$ ano do ensino Médio estuda as estruturas celulares e as composições químicas remetendo à origem da Terra; e o $2^{\circ}$ ano do mesmo nível concentra-se em aspectos evolutivos abrangendo sucintamente alguns aspectos paleontológicos.

Por este motivo, decidiu-se trabalhar os dois primeiros anos do Fundamental II e Médio, porém com um objetivo: romper com a tradicional aula do professor escrevendo no quadro branco ou negro, explicando o conteúdo e, após o término da mesma,

\author{
Manuscrito: \\ Recebido: 26/09/2017 \\ Corrigido: 06/12/2017 \\ Aceito: 14/01/2018
}

Citation: Alves P.D.S. 2018. Um jogo de tabuleiro humano para auxiliar a aprendizagem de Geologia e Paleontologia na educação básica. 2018. Práticas em geociências: roteiro de campo para compreender a evolução costeira no Rio Grande do Sul, Brasil. Terræ Didatica, 14(2):185-192. URL: http:// www. ige.unicamp.br/terraedidatica/.

Keywords: Natural sciences, high school education, Geology, Paleontology, evolution, ludic activities a aplicação de exercícios do livro ou da apostila. Então, teve-se a ideia de aplicar um jogo lúdico de tabuleiro com perguntas e respostas envolvendo o conteúdo abordado em Geologia e Paleontologia com as seguintes finalidades: verificar o grau de conhecimento trazido pelos discentes; retirar as dúvidas sobre a disciplina; e ao final da atividade, pedir a avaliação dos mesmos para saber o quanto a prática aplicada teve influência no aprendizado.

\section{0 que é Geologia e Paleontologia?}

Geologia vem do grego geo- Terra; logos- estudos, e é a parte da ciência que analisa a história da Terra a partir do registro das rochas (Teixeira et al. 2009).

Mas afinal, o que seria rocha?

Conforme Teixeira et al. (2009) definiram, rocha é um agregado sólido de minerais que ocorre naturalmente por diferentes motivos geológicos e que os une. Dividem-se em três grupos de acordo com o seu modo de formação na natureza: rochas ígneas, sedimentares e metamórficas. As rochas ígneas (do latim ignis- "fogo") resultam do resfriamento do magma que é uma massa de rocha fundida que se origina entre a crosta terrestre e o manto superior. Ao ocorrer o resfriamento das rochas no interior do planeta, estas são classificadas em dois tipos: rochas 
ígneas intrusivas, quando o magma se resfria e força um "caminho" nas rochas vizinhas; e aquelas que conseguem atingir a superfície por meio de erupções, se resfriam rapidamente, sendo denominadas como rochas ígneas extrusivas. A diferença entre essas rochas ígneas é a forma de desenvolvimento dos cristais (Press et al. 2006).

Rochas sedimentares são formadas por compactação ou cimentação de fragmentos ou sedimentos produzidos pela ação de agentes intempéricos, processos químicos (decomposição) e físicos (desagregação) que decompõem as rochas em fragmentos de tamanhos variados, sobre uma rocha já existente (Teixeira et al. 2009). As rochas metamórficas (do grego meta- "mudança", morphe- "forma"), como o seu próprio nome já diz, sofrem mudanças na mineralogia, na sua composição química e textura de uma rocha preexistente (protólito) que pode ser sedimentar, ígnea ou até mesmo a metamórfica. São produzidas sob elevadas pressões no interior da crosta e a uma temperatura de aproximadamente $250^{\circ} \mathrm{C}$, abaixo do ponto de fusão das rochas, mas altas o bastante para se modificarem, porém a forma sólida se mantém inalterada (Press et al. 2006).

Apresentaram-se brevemente os conceitos geológicos. E os paleontológicos, o que seriam?

A Paleontologia, palavra derivada do grego palaios- antigo; ontos- ser; logos- estudos, se ocupa de analisar restos de animais, vegetais ou evidências de suas atividades que ficaram preservadas em rochas, gelo, âmbar e no asfalto. Os restos e evidências são conhecidos como fósseis- do latim fossilis que significa extraído da terra (Iannuzzi \& Vieira 2005). Esta área se fundamenta nas ciências naturais com o objetivo de fornecer dados para a evolução biológica dos seres vivos ao longo do tempo; estimar a datação relativa das camadas das rochas pelo grau de evolução ou pela ocorrência de diversos grupos vegetais e animais fósseis; reconstituir o ambiente em que o fóssil viveu; e auxiliar na reconstituição da história geológica da vida na Terra, pelo estudo das sucessões faunísticas e florísticas preservadas nas rochas (Carvalho 2010).

\section{0 lúdico na aprendizagem}

A palavra "lúdico" vem do latim ludus que significa "brincar" e esta expressão remete além de brincadeiras, jogos e diversão (Sant'anna \& Nascimento 2011). Luiz et al. 2014, definiram a palavra jogo como uma atividade voluntária, executada em um determinado tempo, em um local deliberado, seguindo regras obrigatórias que geram o sentimento de ten- são e alegria ao mesmo tempo, diferenciando-se de qualquer atividade cotidiana. Atualmente o jogo é considerado uma das atividades mais elaboradas pelas crianças/adolescentes por trazer a elas um prazer além de transmitir alegria (Luiz et al. 2014).

Os grandes filósofos, como Platão, Rabelais, Rousseau, Pestalozzi, Dewey, e Montessori, trabalharam em metodologias sobre a atividade lúdica, incluindo o jogo, afirmando que estas ferramentas deveriam ser aplicadas na aprendizagem educacional (Sant'anna \& Nascimento 2011).

Segundo as teorias de Vygotsky... cita que o jogo é um instrumento importante para esse desenvolvimento, sendo que os jogos e suas regras criam nos alunos uma zona de desenvolvimento proximal (ZDP), proporcionando desafios e estímulos para a busca de conquistas mais avançadas, ensinando também a separar objetos e significados (Sant'anna \& Nascimento 2011, p. 21)

Para Piaget o ato de jogar faz com que a criança assimile e transforme a realidade ao seu redor atribuindo ainda, um importante papel no seu desenvolvimento (Sant'anna \& Nascimento 2011).

Conforme a criança vai se socializando o jogo vai adquirindo regras ou então a imaginação simbólica se adapta de acordo com as necessidades da realidade. O símbolo de assimilação individual dá espaço às regras coletivas, objetivos ou aos símbolos representativos ou a todos (Luiz et al. 2014.)

O papel do professor perante a alguma atividade lúdica é referente a organização desta, a linguagem, a sua própria atuação no controle do jogo mantendo cuidado e clareza nos objetivos almejados da prática além de estimular o imaginário do discente trazendo como resultado um enriquecimento para a atividade (Luiz et al. 2014). Outro item a ser ressaltado é quanto ao conhecimento trazido pelo aluno. O docente ao propor alguma atividade lúdica já tem que compreender as diferentes formas de brincar de seus discentes e, se possível, devem aproveitá-las para aplicar na sua metodologia (Sant'anna \& Nascimento 2011).

Depois de muitos impasses e discórdias, aos poucos, os educadores veem o ato de adquirir conhecimento por meio de brincadeiras como uma forma de desenvolver o senso crítico, reflexivo e ativo da criança além de estimular o trabalho em conjunto, a responsabilidade e o aperfeiçoamento das funções cognitivas (percepção, atenção, memória e linguagem) e sociais (Sant'anna \& Nascimento 2011). 


\section{Metodologia}

A primeira aplicação da atividade lúdica teve início no segundo semestre do ano de 2016, especificamente entre o período de 27 de setembro de 2016 à 04 de outubro de 2016, no Colégio Instituto Padre Leonardo Carrescia - IPLC, localizado na Rua Barão de Itapagipe, número 96, Rio Comprido, Rio de Janeiro, RJ. A segunda aplicação da prática ocorreu no mesmo estabelecimento/ local citado anteriormente e perdurou o primeiro semestre do ano de 2017, iniciando-se no mês de março e terminando no mês de junho.

Em uma ordem cronológica, os professores apresentavam primeiro o conteúdo almejado da atividade de forma teórica e após uma ou duas semanas era empregada o jogo lúdico. Ocorria está variação de acordo com a programação do calendário escolar.
Escolheram-se as duas primeiras séries do Ensino Fundamental II ( $6^{\circ}$ e $7^{\circ}$ ano $)$ e as duas primeiras séries do Ensino Médio ( $1^{\circ}$ e $2^{\circ}$ ano) devido ao planejamento escolar que trabalha no Fundamenta II com as conceituações das áreas escolhidas para a realização deste trabalho e para o nível Médio, além de seguir o conteúdo programático, aproveitou-se a administração de aulas práticas no laboratório (monitoria) na área da Biologia ofertado pelo colégio.

O jogo de tabuleiro nomeado como "Origem da Terra e suas características.”, foi criado com quatro modelos diferentes, variando o nível das perguntas. Esta metodologia aplicou-se em quatro níveis diferentes de ensino: dois jogos lúdicos para o Ensino Fundamental II e outros dois para o Ensino Médio (Fig. 1a, 1b, 1c e 1d). As referências para a montagem dos questionários necessitaram do uso da biblioteca do IPLC porque

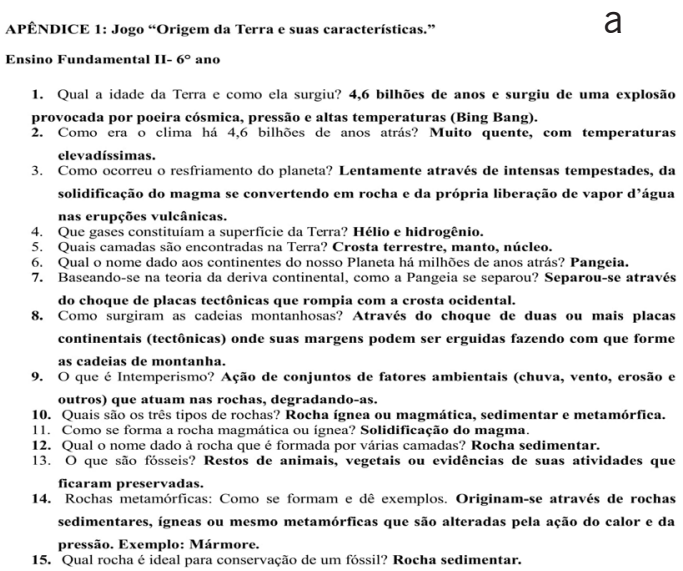

Figura 1. a. Questionário do jogo para o $6^{\circ}$ ano do EF II. b. Questionário do jogo para o $7^{\circ}$ ano do EF II. c. Questionário do jogo para o $1^{\circ}$ ano do EM. d. Questionário do jogo para o $2^{\circ}$ ano do $E M$

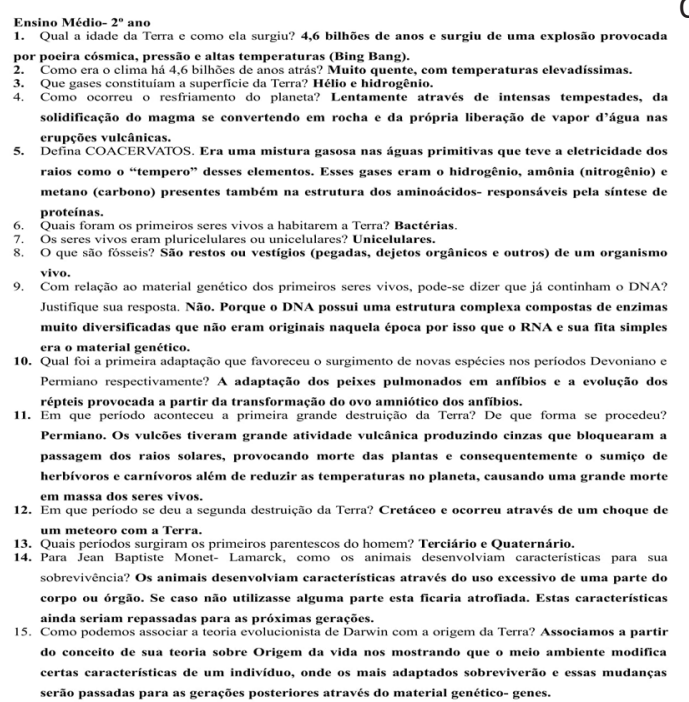


o material usado pelos professores em sala de aula é de um portal digital acessado via Ipad (portal UNO), indisponível para a utilização de terceiros, porém se seguia o conteúdo programático disponível neste portal.

As perguntas para o $6^{\circ}$ ano do EF II tem relação com a formação da Terra, classificação de rochas e teoria das placas tectônicas. Estas perguntas foram preparadas com base no que os autores FAEZ, FAGUNDES e TAKAMATSU (2013) conceituaram. As questões com o conceito de fóssil e surgimento de cadeia montanhosa já tiveram base no autor GEWANDSZNAJDER (2012) enquanto que para a série do $7^{\circ}$ ano, usou-se as definições da autora GARCIA (2012) nas questões que relatavam a formação do planeta e as teorias evolutivas. Quando trabalhado a questão da conceituação de fóssil, baseou-se na Edição Educativa da Editora Moderna (2014) que fez uma abordagem clara e objetiva sobre o assunto.

No $1^{\circ}$ ano do EM refez-se perguntas do $7^{\circ}$ ano do EF II quanto ao surgimento do planeta, porém as questões que abordavam as teorias citológicas tiveram apoio nas definições utilizadas pelos autores LINHARES e GEWANDSZNAJDER (edições dos anos de 2008 e 2009) e quando se trabalhou o questionário do $2^{\circ}$ ano do $\mathrm{EM}$, também reviram algumas perguntas usadas no $7^{\circ}$ ano do EF II com exceção das que continham informações sobre os eventos registrados na escala geológica onde usou-se os dados dos autores MARCONDES (2008) e LINHARES e GEWANDSZNAJDER (2009).

Todos os questionamentos tiveram o objetivo de verificar as denominações dos principais objetos estudados na área de Geologia e Paleontologia agregando com as hipóteses da origem do Universo (teoria de Bing Bang, Criacionismo e Panspermia) mais a escala geológica associada com as teorias evolutivas de Lamarck e Darwin, diferenciando-as.

A ideia de criar um questionário de avaliação para os educandos após a prática, surgiu depois do trabalho feito por IZAGUIRRY et al. (2013) e NEVES, CAMPOS e SIMÕES (2008) ao qual realizaram diversas didáticas na área de Paleontologia e ao final de cada uma era aplicado uma avaliação para saber o quão proveitoso e informativo foram as práticas na aprendizagem dos discentes. Este questionário, como observado na figura 2, teve aplicação num prazo máximo de uma semana após a atividade extracurricular.

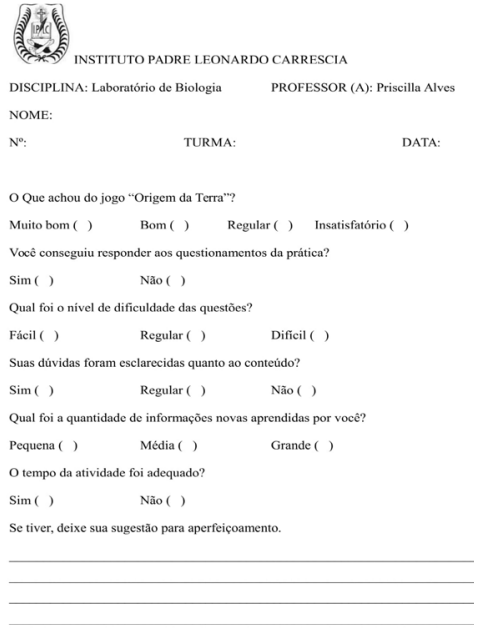

Figura 2. Questionário opinativo para os discentes avaliarem o jogo

\section{Material e procedimento}

O jogo foi feito com folha de papel ofício colorida (verde, amarela, azul clara e branca) e papel cobalto azul escuro. A descrição das casas foi feita manualmente com caneta esferográfica com coloração azul, vermelha, verde, lápis e canetas permanentes de cor azul e preto e usado tinta guache branca, vermelha e azul como observado na figura 3.

Para aplicar a prática, utilizou-se três instalações do colégio (Fig. 4): o pátio escolar, o laboratório de Biologia que também é dividido com as disciplinas da química e física; e a sala de aula para uma turma do $6^{\circ}$ ano do EF.

Ainda necessitou utilizar uma câmera fotográfica para registrar alguns momentos da atividade lúdica e as perguntas estavam contidas num documento do programa Word do celular para evitar que os discentes pudessem visualizar antes o que ia ser perguntado.

No exercício da prática, cada grupo escolheu o seu representante que seria o pino. As regras foram simples: ao lançar o dado, perguntava-se a questão da casa selecionada e o aluno pino só avançaria para o local selecionado se seu grupo acertasse a pergunta, caso contrário permaneceria na mesma casa. Enquanto a pergunta era feita para um grupo, o outro aguardava sentado para evitar a escuta da pergunta / resposta á que as casas só continham uma única pergunta.

Em 2016, o $1^{\circ}$ ano do Ensino Médio foi o primeiro grupo a participar, porém ocorreram duas divisões: no dia 27 de setembro de 2016 

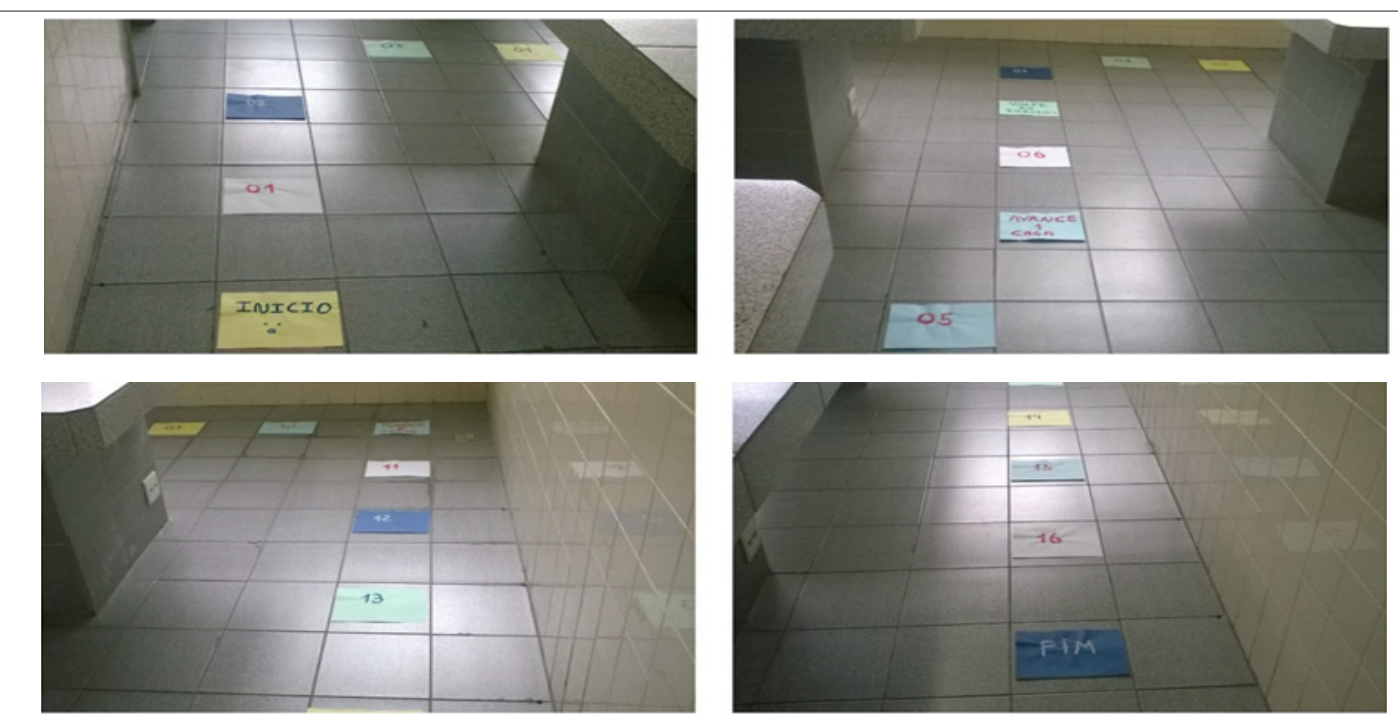

Figura 3. Mosaico do tabuleiro montado no laboratório de Biologia do IPLC para o jogo do $1^{\circ}$ ano do EM (ano base 2017)

somente os alunos ímpares compareceram na aula laboratorial de Biologia, disciplina extracurricular ofertada para agregar pontos na matéria, e estes ainda se dividiram em 2 grupos, por ordem alfabética, com 10 alunos cada. Neste grupo dos ímpares, ocorreram 4 ausências. No $2^{\circ}$ ano do Ensino Médio também ocorreram duas divisões entre o grupo dos alunos ímpares ao qual cada grupo ficou com 8 alunos porque manifestou-se 5 ausências nesta data.

No dia 04 de outubro de 2016 a participação foi continuativa, porém desta vez com os alunos pares tanto do $1^{\circ}$ ano quanto do $2^{\circ}$ ano do EM. Estes foram divididos em 2 grupos com 12 e 8

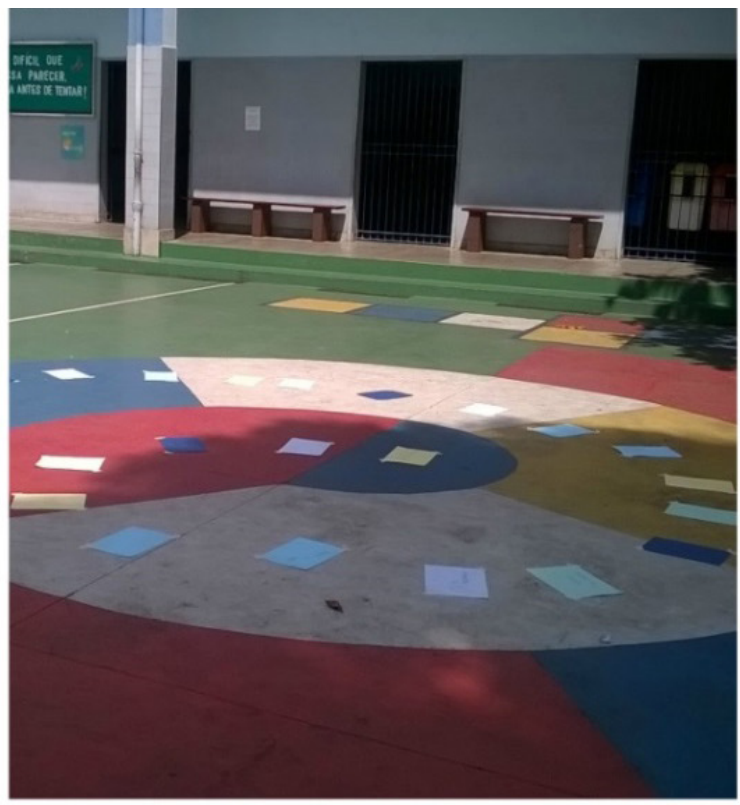

discentes em cada grupo respectivamente. Todos os alunos selecionados do nível médio jogaram no próprio laboratório.

No Ensino Fundamental II, a primeira série a participar do jogo foi o $7^{\circ}$ ano, especificamente a turma 710 , onde se realizou a mesma divisão de grupo: 2 grupos selecionados por ordem alfabética observando 1 ausência nesta turma. Com esta classe a atividade foi realizada no dia 28 de setembro de 2016 no pátio do IPLC (Fig. 5). Na turma 711 a atividade foi aplicada no dia posterior ao da turma 710, 29 de setembro de 2016 e fez-se o mesmo procedimento e no mesmo local: alunos divididos por ordem alfabética no pátio. Nesta turma ocor-

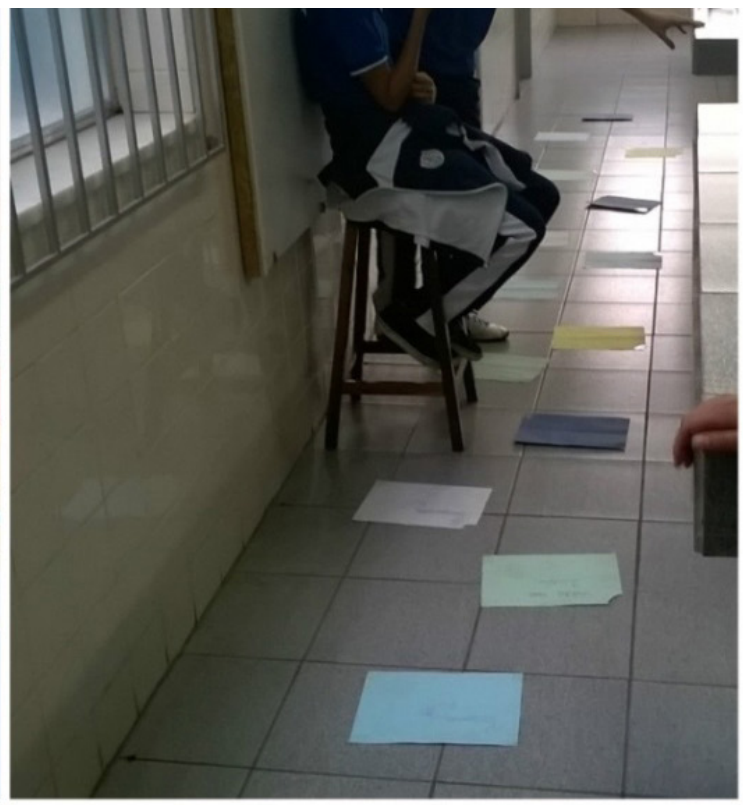

Figura 4. Tabuleiro do jogo no pátio e laboratório do Instituto Padre Leonardo Carrescia (A). (B) imagem com os alunos "pinos" do $6^{\circ}$ ano EF II (2016) 
reram 2 ausências e ambas as turmas participaram da atividade lúdica no pátio do colégio.

Para o $6^{\circ}$ ano do Ensino Fundamental II, a atividade foi concluída no dia 04 de outubro de 2016 para as turmas do colégio. Tanto para a turma 610 quanto para a 611 houve a divisão de 2 grupos por ordem alfabética diferenciando somente o local de aplicação do jogo: a turma 610 fez no laboratório de Biologia enquanto que a turma $611 \mathrm{fez}$ na sala de aula habitual como já comentado anteriormente. Na turma 610 ocorreram 3 ausências no dia da aplicação do jogo enquanto que na turma 611 não manifestou ausências.

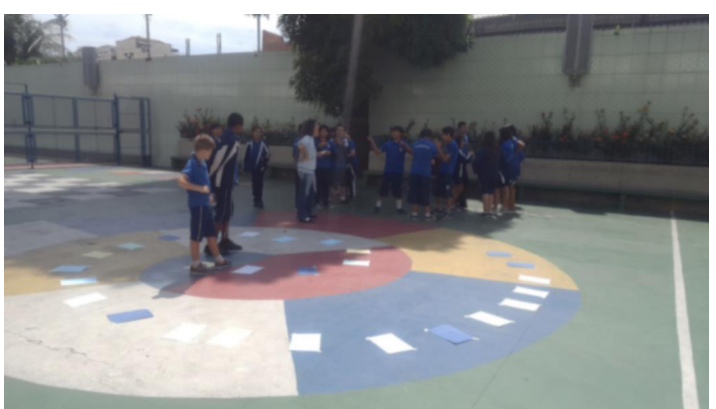

Figura 5. Alunos do $7^{\circ}$ ano (turma 710) do ano 2016 jogando no pátio do colégio Carrescia.

No ano de 2017 decidiu-se aproveitar o mesmo espaço e verificar as mudanças dos discentes perante a aprovação/reprovação no ano letivo 2016. Então os alunos do $6^{\circ}$ ano do Ensino Fundamental II, que participaram do jogo lúdico em 2016.2, estavam no $7^{\circ}$ ano em 2017 , assim como foi para quem participou da prática no $1^{\circ}$ ano do EM em 2016 que atualmente estava cursando o $2^{\circ}$ ano do mesmo nível. As principais alterações ocorridas foram no público do $6^{\circ}$ ano do EF II de 2017 que foram alunos oriundos de outra escola mais aqueles que já cursavam o $5^{\circ}$ ano do Ensino Fundamental I na mesma unidade escolar. O mesmo processo se procedeu no $1^{\circ}$ ano do EM de 2017 que era compostos de discentes vindos de outras unidades escolares mais aqueles presentes desde do $9^{\circ}$ ano do EF II com uma ressalva: no nível do $9^{\circ}$ ano não se fornecia Ciências/ Biologia no Carrescia. A coordenação pedagógica preferiu substituí-la pelas disciplinas da Física e Química retomando os conhecimentos biológicos na série do $1^{\circ}$ ano do nível Médio. Os alunos do $7^{\circ}$ ano do nível Fundamental II e $2^{\circ}$ ano do Ensino Médio aprovados para as séries subsequentes, e que participaram da dinâmica, não tiveram a oportunidade de refazer a prática devido a alteração do conteúdo programático de cada série que já não incluiu o tema abordado neste trabalho (Geologia e Paleontologia).

Aproveitou-se a aula laboratorial da turma 1001 do dia 07 de março e 14 de março para aplicar o jogo. O grupo dos alunos ímpares participaram no primeiro dia e o grupo par no segundo onde ocorreu, novamente, a divisão de 2 grupos com 8 alunos cada, separados por ordem númerica no primeiro grupo (ímpar) e 2 grupos, também em ordem numérica com 8 discentes em cada, para o segundo grupo (par). A turma era composta de 34 alunos e tanto nos ímpares quanto nos pares só teve 1 ausência de cada grupo, totalizando 32 participantes presentes em ambos os dias.

Para a turma 2001, que possuem 48 alunos registrados na pauta de frequência, a prática ocorreu no dia 02 de Maio para os alunos com numeração ímpar e 09 de Maio para os educandos pares onde ocorreram 1 ausências no primeiro grupo e outras 10 faltas no segundo grupo, concluindo, portanto, a participação de 37 discentes. Os grupos tiveram a divisão de 2 grupos separados em ordem numérica com 11 e 10 alunos em cada, totalizando 21 alunos no grupo ímpar e 16 alunos no grupo par. Ambas as séries $\left(1^{\circ}\right.$ e $2^{\circ}$ ano EM) utilizaram o laboratório para a aplicação da atividade.

A terceira série à participar da atividade foi o $6^{\circ}$ ano do Fundamental II que procedeu-se no dia 18 de Maio e não houve ausência de alunos, totalizando a participação de 32 alunos, porém um dos participantes deixou de entregar o questionário avaliavo do jogo pois perdeu o formulário no intervalo para o lanche (a prática ocorreu um tempo antes do recreio). Nesta série ocorreu a divisão de 2 grupos por ordem numérica, havendo 16 alunos em cada e utilizou-se o espaço do pátio coberto localizado em frente a cantina do IPLC.

Para finalizar a atividade lúdica, no dia 26 de junho, o jogo foi aplicado para o $7^{\circ}$ ano do Ensino Fundamental II, porém no dia da prática, os discentes fariam teste de Geografia e infelizmente não conseguiram jogar o tabuleiro completo, avançando diretamente para a última casa e consequentemente para a última pergunta. Houve 1 ausência na turma 710 e por este motivo teve-se a participação de 36 alunos no jogo que foram divididos em 2 grupos os quais foram compostos por 18 discentes cada. O espaço uitilizado para a aplicação da atividade foi o pátio aberto localizado ao lado do pátio fechado como observado na figura 6 . 


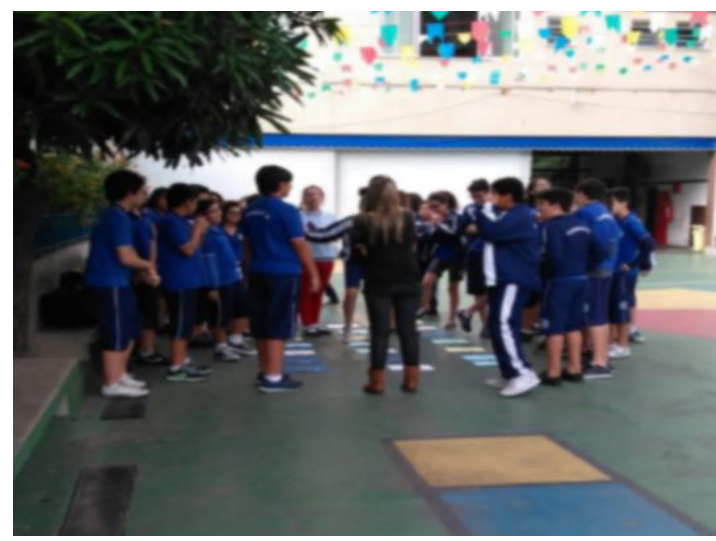

Figura 6. Alunos do $7^{\circ}$ ano (turma 711) do ano 2016 jogando no pátio do colégio Carrescia

\section{Resultados}

O jogo trouxe a questão de fixar e revisar o conteúdo já dado sobre Geologia e Paleontologia e Evolução de acordo com o conteúdo programático e por isso cada série teve a aplicação da prática em dias diferentes exceto o $6^{\circ}$ ano do Fundamental II do ano 2016 no qual a prática aplicou-se numa aula de substituição da ausência da professora que não pôde comparecer por motivos pessoais e não encaminhou nenhuma atividade extra para as duas turmas da época (610 e 611). Conforme observado durante o jogo e registrado na tabela 1 , tanto os alunos do $6^{\circ}$ quanto do $7^{\circ}$ ano do EF II lembraram mais o conceito de rocha (as diferenças composicionais existentes entre elas) e as teorias evolutivas, até porque o conteúdo abordado estava mais recente na memória, quando comparado às respostas do nível Médio. Estas observações foram feitas para o período de 2016.2 e 2017.1. Ressalva-se que o $7^{\circ}$ ano, especificamente na turma 710 , teve dificuldades para responder sobre a composição gasosa na Terra primitiva por desconhecer o elemento químico Hélio (He).

Ambas as turmas do $7^{\circ}$ ano responderam sobre teorias evolucionistas de maneira incompleta ocorrendo uma junção de informações do grupo selecionado para responder à pergunta. A série do $1^{\circ}$ ano de 2016 sentiu mais dificuldade em responder às questões relacionadas ao surgimento das organelas celulares, principalmente a adaptação da mitocôndria e cloroplasto no meio intracelular de um procarionte. Outro ponto que manifestou dúvidas foi quanto ao meio de obtenção de alimentos, pois os alunos acreditavam que os seres autotróficos teriam surgido primeiro que os heterotróficos, mas verifica-se na literatura o oposto. Outra dificuldade perceptível foi perante a definição dos coacervatos. Os alunos do $1^{\circ}$ ano ou desconheciam qualquer fenômeno ocorrido, moléculas participantes ou respondiam a questão com metade das informações, sendo complementados pelo instrutor da atividade. Quanto ao $2^{\circ}$ ano do EM, os educandos apresentaram dúvidas e dificuldades nos eventos da escala geológica (as grandes extinções e os períodos), por causa da ausência de aulas sobre este conteúdo, por mais que os livros trabalhem, os docentes não se atentam à este tema para cobrar em avaliações e ainda detectou-se dificuldade para responder as principais adaptações evolutivas dos seres vivos (surgimento do pulmão, membros locomotores e ovo amniótico).

A descrição do que são fósseis foi o que os discentes, sejam estes das duas séries do Fundamental II ou dos 2 primeiros anos do Médio do ano de 2016, responderam incompleto, sempre associando o conceito com somente preservação de ossos e esquecendo ou desconhecendo a parte dos vestígios e restos. Houve ainda questionamentos com relação ao tempo que um indivíduo leva para se tornar fóssil.

Durante o período de 2017.1, os alunos participantes do $1^{\circ}$ ano do Ensino Médio compreenderam melhor a formação das primeiras moléculas quando comparados com a turma do ano passado, porém não conseguiram associar o nome coacervatos com o processo biológico- químico que se procedeu.

Esta melhora aconteceu porque os discentes já tinham relembrado no início deste ano a origem da Terra, teorias e o surgimento da vida no planeta igual ao ocorrido com o $2^{\circ}$ ano do EM no qual o jogo também teve caráter revisional na parte da Evolução do filo Chordata ${ }^{1}$ mas ocorreu o acréscimo das teorias evolucionistas de Lamarck e Darwin comentadas nas aulas anteriores a prática juntamente com o questionamento sobre a aplicação das teorias com os aspectos evolutivos do filo. Perante a esta última informação, verificou-se as dúvidas na conceituação das teorias, adaptações evolutivas dos indivíduos e a assimilação dos conceitos com os processos evolutivos nas espécies deste filo.

Para as duas séries do Ensino Médio, tanto do ano de 2016.2 quanto do ano de 2017.1, houve ainda a elaboração de um resumo que foi encaminhado para os e-mails de cada turma (1001 e 2001 dos 2 anos) com um texto base para os alunos estudarem

1 Chordata: É o agrupamento de animais, incluindo o homem, que compartilham a característica da notocorda - bastão semi- rígido de células envolvidas por uma bainha fibrosa (HICKMAN et al 2004.). 
Tabela 1. Dificuldades apresentadas no jogo com as respectivas séries

\begin{tabular}{|c|c|}
\hline Séries & Dificuldades apresentadas \\
\hline $6^{\circ}$ Ano - 2016.2 & Conceito de fóssil \\
\hline $7^{\circ}$ ano -2016.2 & Composição atmosférica no início, teorias de Lamarck e Darwin; maneira de obter alimento \\
\hline $7^{\circ}$ ano -2017.1 & Composição atmosférica no início, teorias de Lamarck e Darwin \\
\hline $1^{\circ}$ ano -2016.2 & Teoria endossimbiótica e conceito de coacervados \\
\hline $1^{\circ}$ ano -2017.1 & Teoria endossimbiótica e conceito de coacervados \\
\hline $2^{\circ}$ ano -2016.2 & $\begin{array}{c}\text { Escala geológica, principais adaptações evolutivas e a assimilação desses fenômenos com teorias } \\
\text { evolucionistas }\end{array}$ \\
\hline $2^{\circ}$ ano -2017.1 & Principais adaptações evolutivas e a assimilação desses fenômenos com teorias evolucionistas \\
\hline
\end{tabular}

e conseguir responderem às perguntas.

No $6^{\circ}$ ano, a dificuldade apresentada foi no questionamento sobre a formação de cadeias montanhosas e no $7^{\circ}$ ano, por ter ocorrido num intervalo de tempo menor, não foram notadas dúvidas quanto aos questionamentos sobre o jogo.

\section{Considerações Finais}

A pesquisa de caráter investigativo buscou analisar a finalidade e funcionalidade das práticas lúdicas no ensino de Geologia e Paleontologia relevando alguns conceitos de Evolução na aprendizagem de Ciências / Biologia para alunos do Ensino Fundamental II e Médio. Foi aplicado no colégio Instituto Padre Leonardo Carrescia - Rio de Janeiro foi possível verificar que está didática teve um elevado grau de aceitação pelos discentes além de contribuir com a finalidade principal deste trabalho: reforçar os conteúdos estudados, principalmente quando a atividade foi aplicada em véspera de avaliações sejam estes testes ou provas. Observou-se também que o comportamento das turmas que eram consideradas mais "agitadas" sofreu alteração para melhor, principalmente quando os alunos se viram longe do quadro branco e dos recursos utilizados pela docente num dia tradicional de aula com conteúdo novo.

A premiação dada ao final do jogo também teve seu papel essencial, principalmente para romper com o sentimento de ganhador / perdedor: foi ofertado um bolo, repartido entre os participantes, incluindo a professora que auxiliou no comando e instruções da atividade do $6^{\circ}$ e $7^{\circ}$ ano.

Para os docentes, aconselha-se a partir deste trabalho, a retirar um tempo de aula (50 minutos) de algum conteúdo biológico para aplicar uma atividade lúdica, mesmo que seja com aspecto revisional como foi o caso deste trabalho, para aliviar a tensão e a monotomia das aulas até mesmo porque depois de um ano (transferência do $6^{\circ}$ para o $7^{\circ}$ ano do
Fundamental II), os alunos conseguiram responder ao que era perguntado, confirmando a ideia de aprendizagem e memorização com o método.

\section{Referências}

Carvalho I.S. 2010. Paleontologia. Volume 1: Conceitos e métodos. 3 ed. Rio de Janeiro: Interciência. $734 \mathrm{p}$.

Faez A.C.A.G., Fagundes N., Takamatsu R. 2013. Ciências. Livro 1, $6^{\circ}$ ano. São Paulo: Poliedro. 196p.

Garcia E., Valle M.G., Retondo C.G., Reis C.Q.M. 2012. Ciências em cena $7^{\circ}$ ano. 3 ed. São Paulo, Sem Ed.

Gewandsznajder F. 2010. Ciências planeta Terra $6^{\circ}$ ANOProjeto Teláris. Rio de Janeiro: Ática, 2012. 268p.

Hickman C.P., Larson A., Roberts L.S. 2004. Princípios Integrados de Zoologia. 11 ed. Rio de Janeiro: Guanabara Koogan. 872p.

Iannuzzi R., Vieira C.E.L. 2005. Paleobotânica. Porto Alegre: UFRGS Ed. 167p.

Izaguirry B.B.D., Ziemann D.R., Muller R.T., Dockborn J., Pivotto O.L., Costa F.M., Alves B.S., Ilha A.L.R., Stefenon V.M., Silva S.D. 2013. A Paleontologia na escola: Uma proposta lúdica pedagógica em escolas do município de São Gabriel- RS. São Carlos: Cadernos da Pedagogia, 7(13):2-16.

Linhares S., Gewandsznajder F. 2009. Biologia. Vol. único. Rio de Janeiro: Ática. 552p.

Linhares S., Gewandsznajder F. 2008. Biologia Hoje 1. 15 ed. Rio de Janeiro: Ática. 432p.

Luiz J.M.M., Santos A.C.B., Rocha F.F., Andrade S.C., Reis Y.G. 2014. As concepções de jogos para Piaget, Wallon e Vygotski. Buenos Aires: Revista digital EFDeportes.com, 19(195):1-13.

Marcondes A.C. 2009. Biologia e cidadania, Ensino Médio. Vol. 2. São Paulo: Escala Educ. 552p.

Neves J.P., Campos L.M.L., Simões M.G. 2008. Jogos como recurso didático para o ensino de conceitos paleontológicos básicos aos estudantes do Ensino Fundamental. Ponta Grossa: Terr@Plural, 2(1):103-114.

Press F., Siever R., Grotzinger J., Jordan T.H. 2006. Para entender a Terra. 4 ed. São Paulo: Artmed, 768p.

Sant'anna A., Nascimento P.R. 2011. A história do lúdico na educação. Florianópolis: Revemat, 6(2):19-36. 